Journal of History Culture and Art Research

Revue des Recherches en Histoire Culture et Art

مجلة البحوث التاريخية والثقافية و الفنية
Vol. 2, No. 2, June 2013

Copyright (C) Karabuk University

http://kutaksam.karabuk.edu.tr/index.php

Özel Sayı/Special Issue

(English Studies)

DOI: 10.7596/taksad.v2i2.248

\title{
Approaches To The Teaching Of Introductory Literature Courses In A Polish English Language Teacher Training College
}

\section{Andy DIXON*}

\begin{abstract}
The purpose of this paper is to outline approaches to a course entitled Introduction to Literature, which is frequently available to second-year undergraduates in Polish teacher training colleges and other institutes of higher education. While preparing students for subsequent courses in British and American literature and helping them towards mature responses to literary texts, the course aims to raise student teachers' awareness of the potential of literature in the learning/teaching situation and to provide them with examples of the integration of curricular areas. In addition, given that literature is an intrinsically interesting source of authentic language, it is intended that instruction should increase students' sensitivity to language and expand their vocabulary, thus promoting the development of the four skills.
\end{abstract}

Keywords: teaching/learning literature; introductory courses; higher education; vocabulary expansion; language skills.

\footnotetext{
${ }^{*}$ University of Sussex, Lecturer in English Language and Literature.
} 


\section{Background}

The teaching of literature courses in the majority of tertiary institutions in Poland tends to remain conservative and classroom activity predictable. Frequently, a historicoliterary survey of the high points of the canon from Beowulf to Virginia Woolf (and sometimes beyond) is attempted. Teachers begin with high ideals and no few ideas, but, overwhelmed by the volume of the material they are required to cover, and faced with reluctance on the part of students, owing to heavy workloads, to undertake more than a bare minimum of reading, they tend to resort mainly to lecture-based approaches.

In 1990-1991 the majority of Poland's approximately 50 English Language Teacher Training Colleges were established with the objective of providing the nation with 20,000 primary, secondary and vocational school teachers by the early years of the $21^{\text {st }}$ century. These colleges, which offer three-year, licentiate courses inherited a highly academic university syllabus from the Ministry of Education.

However, the purpose of this paper is to outline the approaches to, aims and objectives, and methods of evaluation of an Introduction to Literature course which is frequently, although not invariably, available to students. The advantage of this particular course is that it lacks detailed syllabus guidelines and thus those who teach it have the luxury of considerable methodological and pedagogical flexibility and virtually complete freedom in the selection of texts. It is thus possible, given that literature is an intrinsically interesting source of authentic language, to use a variety of literary texts to the end of promoting the development of the four skills.

\section{Changing Attitudes to the Teaching of Literature}

In the early years of communicative language teaching, literature still bore the stigma of its attachment to the grammar-translation method, one of the goals of that method being the study of a "language in order to read its literature" (Richards and Rogers, 1986: 3). During the same period it was argued by proponents of the English for Specific Purposes movement that the teaching of literature was not relevant to the vocabulary and language forms a learner needs in order to accomplish particular tasks in English. However, the last two decades have seen the rehabilitation of literature, and its use in the language classroom gathering momentum for, as Brock has pointed out, the focus on "the meaningful, communicative use of English in the classroom" was destined eventually to be accompanied by "suggestions that literature should play a larger, more central role in teaching" (1990: 22). Dissent, where it still 
exists, now tends to take the form of objections not to the use of literature in the classroom per se but to the imposition, for example in African ESL contexts, of texts which are felt to be irrelevant, or even hostile, to the experience of learners (Thiong'o, 1986: 223-229). Thus the question for most practitioners is no longer whether or not to teach literature, but rather what to teach and how best to teach it given the exigencies of their particular professional context.

\section{Aims and Objectives of the Introduction to Literature Course}

It is important, particularly in a teacher training college context, that the Introduction to Literature course should raise student teachers' awareness of the potential of literature in the learning-teaching situation and enable them to experience a range of procedures for dealing with texts in the communicative language classroom. Students' general language awareness should be expanded and their literary competence developed, thus helping them towards informed evaluations and interpretations of texts, and, ideally, the reading of literature for pleasure. They should also be helped to equip themselves with suitable language "to articulate and extend their initial responses" (Hall, 1999: 11). Furthermore, learners' knowledge of the world should be expanded and an opportunity provided to explore, through literature, socio-cultural aspects of English in a variety of settings.

In addition, it is one of the aims of my course to provide students with examples of the integration of the curricular areas of practical English, methodology and literature. However, the primary objective of the course is to promote language learning and, with this goal in mind, the teacher should have a clear idea of what he or she hopes to achieve based on a thorough awareness of the communicative needs of the student group. In my own context, I aim to foster high levels of proficiency in all four skills, mindful of the fact that some of the students on graduating will indeed enter the teaching profession and thus become models for their own students. Others will go on to university for two further years of study in order to complete the master's programme before, in a significant number of cases, also ending up in the classroom.

Finally, as the students have arrived at the Training College from a background in which the literary text is seen as an achieved structure of meanings, it is important that they are shown how they can become producers rather than mere consumers of a text. It is thus a further aim of the course to make participants feel that they have the freedom to experience literature as they wish, rather than, as they suspect, they ought. As Murdoch notes, the impact in the communicative classroom of encouraging "a plurality of responses ........ makes the study of literature such a suitable basis for interaction" and "will result in a development of students' language skills" (Murdoch, 1999: 2). 


\section{The Role of Literary Texts in Promoting Skills' Development}

Short fiction is most useful in developing the advanced levels of reading competence and language awareness that the students should be aiming for. Appropriately chosen texts offer rich material for detailed work in authentic contexts on lexis and syntax. They also raise students' general language awareness (Lazar, 1993: 15), sensitise them to connotation, collocation, register and style and tend to provoke strong responses, which can be expressed both verbally and in writing. And extensive reading, which stems from the course, as Grellet (1981: 4) notes, contributes to the development of fluency.

The literary essay can be beneficially utilised at advanced levels in a number of ways. Literary essays can be read for their aesthetic qualities, but also, importantly, for their referential and expository elements. They provide virtually unlimited scope for the development of reading micro skills and thus are a useful supplement to the texts that are employed in specialised reading classes. Essays written with argumentative and persuasive intentions are particularly useful as, in addition to inviting a variety of responses, they can provide students with insight into structuring an argument, paragraph linking and development, and audience awareness, all of which will be of benefit to them in their own writing.

Poetry, it has not infrequently been claimed, has a limited place in the language classroom as exposure to unusual or unorthodox language is counter-productive to the development of students' communicative competence. Clearly, poetry which is obscure is unlikely to serve any useful purpose, but poems chosen with careful attention to students' needs and cognitive level can be highly beneficial to the learning process. Poetry, dealing as it does with major human issues, can function as a source of intellectual and emotional involvement and will call forth individual responses stemming from personal feelings, which, as Maley and Moulding observe (1985: 1), "are as important in a foreign language as they are in our own language." And, significantly, as Widdowson (1975) has shown, encouraging the investigation of language which deviates from the norms of standard usage can have the effect of raising awareness of and consolidating those norms.

Drama offers rich opportunities for the development of language skills as it "can create meaningful contexts both for controlled language practice and to stimulate fluency" (Ciechanowska and Dębska, 1998: 63); and, in a teacher training context, it can be a particularly useful source of ideas, many of which can later be employed by the trainees in their own communicative classrooms. Drama is of value in developing the personalities of young teachers, making them aware of their hidden strengths and helping them to learn to capitalise on them. Most drama activities are carried out in groups and this provides experience in cooperation and group management. 


\section{Criteria for the Selection of Materials}

Given that Polish tertiary level students need to be disabused of their assumption that their role in literature lessons will primarily be a passive one, selection of texts is of crucial significance. The approach to literature in schools is in the main academic, students being seen as the recipients of an expert's knowledge, so it is important that the instructor's choice of material is motivating. If the selected works are interesting and involving, it will help students to participate more fully in discussions, which will gradually lead to increased self-confidence and concomitant communicative gains.

Ultimately, it is the learners' needs that are the primary criterion for text selection, but the decision is never easy, particularly for teachers who have yet to meet or work with the students they are about to teach. However, one might usefully take as a general starting point Icoz's advice: "great attention should be paid to the choice of texts in order to ensure that the student's competence in English is adequate, [and] his cognitive development is appropriate" (Icoz, 1992: 24). This can and, indeed, should result in a process in which a large number of intrinsically interesting texts from the instructor's point of view are rejected. It is crucial that the students do not find the material that they are asked to cope with overwhelming for it takes very little for the average Polish student to lapse back into the familiar role of passive recipient of the teacher's interpretations. To use Krashen's terminology, students in introductory courses should be exposed to language at the level of $i+1$ (Krashen, 1985) as it is important to encourage them to strive for comprehension by using context clues to interpret unfamiliar vocabulary.

Many texts require, if they are to be meaningfully processed and discussed, a level of personal and cognitive maturity which can only be the product of long experience and sustained thought. The teacher dealing with students only recently released from secondary schools should reflect on the extent to which the worlds of reader and writer overlap. This is not to make a fetish of relevance but to acknowledge that a 21-year-old Polish learner's life experience and emotional development may preclude an adequate response to the essence of certain literary works, even in the absence of major difficulties of a linguistic nature.

With regard to the accessibility of cultural references, a common-sense approach should prevail. Texts should be chosen which are likely to stimulate curiosity in different approaches to societal organisation but which do not make excessive demands on students' capacity to make imaginative leaps into culturally unfamiliar territory. It should also be borne in mind, as Lazar points out, that "the relationship between a literary text and the culture in which it is produced is highly complex, since few texts are mere factual representations of their culture" (Lazar, 1993: 63). The judicious selection of material from a cultural point of view will result in students coming to a better understanding of their own values and culture and, ideally, should lead to a commitment to the belief that despite the fact that "many of the 
concepts with which we operate are culture-bound......... and vary considerably from culture to culture" (Lyons, 1981: 308) communication across cultural boundaries can, nevertheless, be achieved.

\section{The Short Fiction Component}

Short stories are an important component of most introductory courses as they involve students in authentic reading of distinctly manageable proportions. Potential approaches to the text are manifold and will overlap or vary according to the fictional techniques employed by the author and the thematic areas encompassed. In order to illustrate a number of ways short fiction is treated in the Introduction to Literature course, I shall focus briefly on a work entitled Silkie by the American writer Joyce Carol Oates.

In the case of Silkie, which is set in small-town America in the late 1950s, and which deals with conformity and the need for respectability, I designed a pre-reading activity to exploit the students' personal experiences and draw them into the world of the story. Typically, the class is divided into four groups. Two groups are asked to complete a list of the characteristics and attitudes of small town and village dwellers, while the other two carry out the same task in respect of large town and city dwellers. The lists are then compared and discussion invited. Other pre-reading activities which are useful in preparing course participants for optimal learning opportunities from their encounter with short fiction can include brainstorming certain subjects, setting up brief discussions or debates related to themes which emerge from the work to be studied, describing picture prompts which have some relevance to the story-line and selecting key vocabulary items from the text to stimulate predictive skills. A useful alternative, or additional, activity is of the type suggested by Spack (1985). This involves asking students to write briefly about an incident in their lives which has some bearing on one of the issues which they will later discover is raised in the text. In the case of Silkie, I suggest a topic connected with pressure they might have felt, or perhaps still feel, to conform to certain externally imposed standards; or, alternatively, I invite them to write very briefly about a personal act of rebellion. Owing to the potentially sensitive nature of the subject area, no-one is requested to read his or her piece aloud, but as I also engage in the exercise and offer my own contribution first, there is usually no shortage of volunteers.

While-reading activities can usefully include filling in grids or charts prepared by the teacher, the taking of notes on certain key areas and various annotation exercises. The teacher can also ask the students to pause at the end of certain paragraphs and predict how the story will continue; or, alternatively, if writing is a priority and time available, students can be asked to continue or complete the story on the basis of the title, the first sentence or the introductory paragraph. And in short stories rich in dialogue, concentrating on the characters' utterances can provide useful practice for separating what a person says from what he or she thinks. 
If the choice of the story and the pre- and while-reading activities have proved stimulating, post-reading activities are likely to be a source of enjoyment for both the teacher and the students and will promote rich opportunities for purposeful and meaningful language learning. Activities focusing on the plot can involve writing an alternative ending in pairs or small groups or encouraging students to speculate verbally on how the lives of the characters will develop in the future beyond the conclusion of the text. Another useful exercise is building up profiles of the main characters not only because this leads to an understanding of the roles they play within the story but also because it provides an opportunity for students to take sides and articulate exactly where their sympathies lie.

The writer's methods can be investigated by asking the students to list the main periods and incidents in the protagonists' lives. Students produce anything from five to ten points. For each point they are asked to decide, using the character profile they have developed, whether a particular character's action was predictable and what alternatives were available to him or her.

A challenging activity involves changing the point of view, in the case of Silkie to that of either Nathan or Silkie's mother. The students work in groups discussing how these two other characters might assess the situation and then role plays are developed with Nathan in a bar talking to a friend and Silkie's mother at home confiding in a trusted neighbour. Further role plays are suggested by the climax of the story with volunteers acting out Silkie's provocation of Nathan (a last attempt perhaps to avoid her fate), Nathan's response and the final agreement in which the mother's wishes are respected by her daughter.

Further post-reading activities might include the noting down by students in their reading journals of their general impressions of the story, as well as their emotional responses, as an aid to developing fluency of expression; the identifying of pivotal points and the discussion of their significance; discussion of the literal, symbolic or psychological levels of meaning; the preparing of blurbs for the story; and exercises which involve adding to the text in some way or using it as a springboard for further language work.

Having worked on the text in a structured way, focusing on a number of particularly relevant areas, the students have reached the point at which more general responses to the themes and issues it has raised may evolve. And if the lesson has achieved its aim of being learner-centred, the teacher, to use McCrae's words (1991: 97) having functioned as an "intermediary between author, literary work and receiver" and "open[ed] up a multidirectional sphere of interaction", a plurality of responses should be the result.

Finally, it should be noted at this point that most of the approaches mentioned above are by no means specific to a particular text but may be used in much the same way, or only slightly adapted, in connection with a wide variety of short fictional texts. And this is also the case with regard to exercises and approaches to other genres in the course. 


\section{Literary Essays}

Carefully chosen literary essays can be of considerable use to the teacher of literature. Not only can they be used for their content and as a general source of language discovery and inspiration but also for developing reading micro-skills. They function, too, as models of highly effective written communication.

An essay which lends itself to particularly effective exploitation from an aesthetic point of view and which provides an excellent example of the writer's craft is George Orwell's A Hanging. Students can be asked at the outset to skim the text to establish the author's thesis and then, with the aid of a worksheet containing a variety of exercises, be helped to move through the essay step by step discovering the manner in which Orwell conveys his gradual realisation of the full implications of capital punishment. The lesson ends with a consideration of the extent to which the author is successful in presenting his case and possibly a discussion on the issue of capital punishment.

While they are working on literary essays students should be encouraged to see writing not as an isolated act but as an integral part of human communication and as a process of developing and structuring ideas. The text, in effect, acts as a model for writing, the teacher's function being to highlight its various discourse features. The composing of formal, well-structured and coherent essays is particularly challenging for Polish learners of English as Slavic and English academic writing conventions differ. Basically, Polish academic writing tends to be digressive, somewhat baroque and characterised by a variety of standpoints making it to a certain degree reader-responsible, whereas British and American academic styles are writer-responsible (Connor, 1996). It is important, therefore, to ensure that students' opportunities for practising a mode of expression that is foreign to them in more ways than one are maximised.

The essay component in the Introduction to Literature course functions conveniently as a supplement to the academic reading and writing courses that are characteristic of the latter stages of the practical English programme in Polish English Language Teacher Training Colleges.

\section{THE POETRY COMPONENT}

As far as poetry is concerned, I concur with Ciuk (1995: 107) on the effectiveness of a thematic approach. One can take universal themes such as carpe diem, war and peace, death, growing old and relationships between lovers or family members and generate, even with reticent learners (as Poles often are) meaningful interaction with the text, which is confirmed by students' varied responses. Poems are, as Hall (1999: 11) notes "a source of authentic language" characterised by "an unmistakably individual voice", and, if appropriately selected 
and used should strike a responsive chord in the consciousness of readers resulting in high potential returns in terms of language acquisition and use.

Traditional academic approaches to poetry should be avoided in the introductory course as they are an invitation to students to lapse into passivity. Poetry might have been described by Aldous Huxley (1963: 12) as an attempt "to speak about the ineffable, to communicate in words what words were never intended to convey"; but the EFL teacher is best advised to regard it as one of many types of language use and a useful source for generating communicative activities.

Poetry can conveniently be used to the end of developing all four practical language skills. Pre-listening or pre-reading activities could include discussing personal experiences as a lead-in to the text, predicting vocabulary items on the strength of the title using a grid or chart divided into probable, possible and unlikely sections, or inventing mini-stories of approximately 50 words based on cue words from the poem. While-reading activities might make use of cloze techniques of a multiple choice gap-fill kind or the selection of appropriate lexical items from a wordlist. Alternatively, students could be asked to assemble a poem from randomly arranged lines or verses. Post-reading activities could involve writing a paraphrase or possibly a personal response, improving on a given but somewhat inaccurate paraphrase or choosing the best paraphrase from a list of three or four provided by the teacher (Maley and Moulding, 1985: 138).

As Anthony Burgess (1974: 7) observes: "Poetry relies ........on the power of words, on their manifold suggestiveness". Ideally, the communicative activities provided by the teacher will contribute to students' understanding of this fact and consequently to the expansion of their language awareness.

\section{Drama and Drama Activities}

Finally, a play is read and this forms the basis for discussion and a number of drama activities. The discussion focuses on characterisation, plot development and the presentation of conflict and this serves as a springboard for a number of drama activities which are prepared and performed in groups. Such an approach, in addition to giving students the chance to put their creative ideas into practice, helps them to develop self-confidence, fosters an atmosphere of co-operation, provides ample opportunities for the development of verbal skills and helps students "to use what they know......with maximum effectiveness in imaginary situations that recreate the challenges and unpredictability of real-life encounters" (Ciechanowska and Dębska, 1998: 63).

In working on role plays, improvisation exercises, the creation of short scenes based on incidents from the play, re-working scenes, and writing followed by acting out short sketches which have either a direct or tangential relationship to parts of the play, students 
learn to extend their range of language and improve their fluency. Given that some of the students taking the Introduction to Literature course will enter the teaching profession, their working actively on drama in a spirit of co-operation, in addition to actually studying a play, will give them an awareness of and insight into the potential uses of drama activities in their own communicative classrooms.

\section{Evaluation}

The Introduction to Literature course is not evaluated with a view to establishing the extent to which the texts studied and various stock responses to them have been memorised, nor with the focus on their explication in the form of the writing of critical appreciations, but rather with the stress on "the ability to do something with the language" (Boyle, 1988: 199).

The examination could be either oral or written. In the former case, the students, in groups of three, are invited to engage in a discussion of two of the poems studied and worked on during the course, the teacher not participating directly, but acting as a facilitator. The poems are taken from the same thematic area in order that comparisons and contrasts can be made. As throughout the course students have been encouraged and helped to interact with poems and to respond to them, the examination situation is usually reasonably comfortable and natural. Credit is given for the ability to demonstrate control of a wide range of appropriate vocabulary, to summarise content, to produce well-supported arguments and for general fluency.

If a written test is preferred, it could involve writing one essay question from a selection of five and in addition contextualising and commenting on four gobbets taken from the short stories and literary essays. Students should be able to demonstrate the techniques and control necessary for the writing of a well-structured critical essay, while the gobbets section tests the ability to relate small sections of text to their wider context but at the same time provides space for personal interpretation and comment.

The aim of the examination is to test language production and, in McRae's words, to "give the student the opportunity to show what has been learned, how that learning has been applied, and how that learning can be expressed" (McRae, 1991: 119).

\section{Conclusions}

One of the most important tasks of the teacher in higher education in Poland, confronted as he or she will be with students who believe that a literary work is imbued with a certain meaning which will gradually be revealed to them, is to encourage interaction with the text. Students need to be made aware that their own subjective responses are valid precisely because as Kramsch (1993: 122) points out, works of literature, by their very nature, "encourage one to enter the writer's subjective world view". In empowering students to eschew the comforts of a teacher-oriented course and genuinely engage with the text, the 
teacher is providing the opportunity for development of the four skills, which, as mentioned, is the primary objective underpinning the Introduction to Literature course. And, importantly, at the same time, he or she is enabling "learners to be in a better position to take on more responsibility for their own learning" (Sinclair, 1996: 142). Hopefully the introductory course described in this paper demonstrates to its participants that literature can be personally enriching, is worth studying for the aesthetic pleasure it offers and is an invaluable resource in the communicative classroom.

\section{References}

Boyle, J.P. (1986) Testing language with students of literature in ESL situations. In Brumfit, C.J. and Carter, R.A. (eds.) pp. 199-207.

Brock, M.N. (1990) The case for localised literature in the ESL classroom. English Teaching Forum, 28,3: 22-25.

Brumfit, C.J. and Benton, M. (eds.) (1993) Teaching Literature: A World Perspective. Basingstoke and London: Modern English Publications/The British Council/ Macmillan.

Brumfit, C.J. and Carter, R.A. (eds.) (1986) Literature and Language Teaching. Oxford: Oxford University Press.

Burgess, A. (1974) English Literature. Harlow: Longman.

Carter, C. and McRae, J. (eds.) (1996) Language, Literature and the Learner. Harlow: Longman.

Ciechanowska, J. and Dębska, A. (1998) Drama for the training of language teachers. In Melia, J.P. (ed.) pp. 61-68.

Ciuk, A. (1993) On teaching literature in English at university level in Poland. In Brumfit C.J. and Benton M. (eds.) pp. 104-107.

Connor, U. (1996) Contrastive Rhetoric. Cambridge: Cambridge University Press.

Grellet, F. (1981) Developing Reading Skills. Cambridge: Cambridge University Press.

Hall, G. (1999) Talking about literature. Modern English Teacher, 8,3:11-14.

Huxley, A. (1963) Literature and Science. London: Chatto and Windus Ltd.

Icoz, N. (1992) Teaching literature: why, what and how. English Teaching Forum, 30,1: 10 11 and 24. 
Kramsch, C. (1993) Context and Culture in Language Teaching. Oxford: Oxford University Press.

Krashen, S.D. (1985) The Input Hypothesis. Harlow: Longman.

Lazar, G. (1993) Literature and Language Teaching. Cambridge; Cambridge University Press.

Lyons, J. (1981) Language and Linguistics. Cambridge: Cambridge University Press.

Maley, A. and Moulding, S. (1985) Poem into Poem. Cambridge: Cambridge University Press.

McRae, J. (1991) Literature with a small " $l$ ". Basingstoke and London: Modern English Publications/Macmillan.

Melia, J.P. (ed.) (1998) Innovations and Outcomes in English Language Teacher Education.Warsaw: The British Council.

Murdoch, G.S. (1992) The neglected text - A fresh look at teaching literature. English Teaching Forum, 30,1: 2-5 and 15.

Richards, J.C. and Rogers, T. S. (1986) Approaches and Methods in Language Teaching. Cambridge: Cambridge University Press.

Sinclair, B. (1996) Learner autonomy and literature teaching. In Carter, C. and McRae, J. (eds.) pp 138-150.

Spack, R. (1985) Literature, reading, writing and ESL: Bridging the gaps. TESOL Quarterly, 19,4: 703-726.

Thiong'o, N. (1986) Literature in Schools. In Brumfit, C.J. and Carter, R.A. (eds.) pp 223229.

Widdowson, H.G. (1975) Stylistics and the Teaching of Literature. Harlow: Longman. 